\title{
O ensino médio e as novas diretrizes curriculares nacionais: entre recorrências e novas inquietações
}

\author{
SABRINA MOEHLECKE
} Universidade do Rio de Janeiro

\section{INTRODUÇÃO}

Em maio de 2011, o Conselho Nacional de Educação (CNE) aprova parecer que estabelece novas diretrizes curriculares nacionais para o ensino médio no Brasil. A medida é apresentada como uma atualização das diretrizes de 1998, entendida como necessária diante das diversas mudanças ocorridas na legislação relativa ao ensino médio nos últimos anos, bem como das transformações em curso na própria sociedade, no mundo do trabalho e no ensino médio. O escopo do debate é amplo, assim como o são as questões que permeiam a definição da própria especificidade desse nível de ensino no país e suas respectivas políticas curriculares.

Pode-se afirmar que esse nível de ensino finalmente alcançou uma identidade própria, como há quinze anos já previa a Lei de Diretrizes e Bases (LDB)? As críticas feitas às Diretrizes Curriculares Nacionais para o Ensino Médio (DCNEM) de 1998, como, por exemplo, sua ênfase excessiva na flexibilização, autonomia e descentralização do currículo, subordinando a educação às demandas do mundo do trabalho, são temas que foram ressignificados nas novas diretrizes?

Diante dos múltiplos olhares e perspectivas a partir das quais é possível analisar as atuais políticas para o ensino médio, pretende-se, neste ensaio, identificar o que as novas diretrizes curriculares trazem de novo para a organização do ensino médio no Brasil. Desse modo, a primeira parte do texto é dedicada à contextualização de algumas 
das principais mudanças pelas quais passou o ensino médio no país, especialmente em termos legais, das condições de acesso e permanência e das políticas na área. Em seguida, são identificadas as principais críticas feitas às DCNEM de 1998 nos estudos e pesquisas realizadas sobre o assunto desde então para, ao final do artigo, se analisar até que ponto as novas diretrizes dialogam com esses questionamentos e inquietações, quais as novas possibilidades de organização do ensino médio que trazem para o país e que desafios continuam na agenda de debates.

\section{CONTEXTO HISTÓRICO DO ENSINO MÉDIO NO BRASIL}

\section{Marcos normativos}

O ensino médio brasileiro, no decurso de sua história, tem sido recorrentemente identificado como um espaço indefinido, ainda em busca de sua identidade. Contudo, observando-se as funções que lhe foram atribuídas nos últimos tempos, não há dúvida a respeito do caráter marcadamente propedêutico a ele associado. Organizado com base no modelo de seminário-escola dos jesuítas, o ensino médio no Brasil nasce como um lugar para poucos, cujo principal objetivo é preparar a elite local para os exames de ingresso aos cursos superiores, com um currículo centrado nas humanidades, pouco relacionado às ciências experimentais (cf. Pinto, 2002).

Algumas mudanças nesse papel exclusivamente propedêutico surgiram com as reformas educacionais iniciadas por Francisco Campos, na década de 1930, quando começou a ser implantado o ensino profissionalizante destinado às "classes menos favorecidas". O então chamado ensino secundário começou a ser reorganizado a partir de 1931 (com o decreto n. 19.890/31), consolidando-se o processo em 1942, com a Lei Orgânica do Ensino Secundário (decreto-lei n. 4.244/42), que dividiu esse nível de ensino em duas etapas - um ginásio de quatro anos e um colegial com três anos -, mantendo tanto os exames de admissão quanto a seletividade que marcava esse nível de ensino.

Nesse primeiro momento de expansão do ensino secundário, o modelo destinado "às massas" foi o profissionalizante, com terminalidade específica, que visava a preparar mão de obra para as indústrias que começavam a surgir no país. Paralelamente, preservou-se o ensino de caráter propedêutico, destinado ao ingresso ao ensino superior. Tais opções consagraram o que educadores da época definiram como uma dualidade do nosso sistema de ensino, com duas trajetórias distintas, de acordo com aqueles a quem se destinavam. A equivalência entre os dois modelos, permitindo o ingresso ao ensino superior também aos que realizassem o curso secundário profissionalizante, foi sendo gradualmente construída (leis n. 1.076/50 e n. 1.821/53), mas só foi estabelecida integralmente com a primeira LDB, em 1961 (lei n. 4.024/61) (cf. Romanelli, 2001).

Outra mudança significativa no denominado $2^{\circ}$ grau (segundo ciclo do ensino secundário) foi a profissionalização compulsória, estabelecida pela lei n. 5.692/71, que 
também unificou o antigo ginásio (primeiro ciclo do ensino secundário) com o primário, formando o $1^{\circ}$ grau. Em pleno regime militar e período ditatorial, tal iniciativa foi associada à necessidade de reduzir a pressão pela ampliação do ensino superior, estabelecendo-se uma terminalidade específica para o ensino médio. Contudo, sua duração foi curta e pouco eficaz, sendo abolida em 1982.

Em 1988, uma nova Constituição Federal foi aprovada, trazendo alterações importantes na abrangência e no caráter do nível de ensino em pauta. Afirmou-se o dever do Estado em asseverar a "progressiva extensão da obrigatoriedade e gratuidade do ensino médio" (art. 208, inciso II), indicando-se a intenção de estendê-lo a toda a população, medida que se refletiu no processo de ampliação da oferta do ensino médio, ocorrida nos anos que se seguiram.

Na segunda metade dos anos 1990, retomou-se o debate sobre as funções do ensino médio. Propõe-se uma maior ênfase nos cursos profissionalizantes. A emenda constitucional n. 14, de 1996, alterou a redação do texto constitucional, substituindo o termo "progressiva extensão da obrigatoriedade" do ensino médio por "progressiva universalização”. A mesma emenda criou o Fundo de Manutenção e Desenvolvimento do Ensino Fundamental e de Valorização do Magistério (FUNDEF), posteriormente regulamentado pela lei n. 9.424/96 que, em consonância com as novas orientações políticas, passou a concentrar a destinação de recursos para o ensino fundamental regular. Contudo, a LDB de 1996, além de manter a redação original da Constituição, consagrou o ensino médio como etapa final da educação básica, definindo-lhe objetivos abrangentes (art. 35) que englobavam a formação para a continuidade dos estudos, o desenvolvimento da cidadania e do pensamento crítico, assim como a preparação técnica para o trabalho, assegurada a formação geral. Ressalta-se, nesse momento, a intenção de imprimir ao ensino médio uma identidade associada à formação básica que deve ser garantida a toda a população, no sentido de romper a dicotomia entre ensino profissionalizante ou preparatório para o ensino superior.

Direção distinta seguiu o decreto n. 2.208/97, aprovado no ano seguinte, ao definir que a formação profissional de nível técnico no país devia ser organizada de modo independente do ensino médio regular, com uma estrutura curricular própria, dissociando-se, assim, a formação geral da técnica. No entanto, tal decreto foi revogado em 2004, sendo substituído pelo decreto n. 5.154 e, posteriormente, pela lei n. 11.741/08, no âmbito de uma nova política, tanto para o ensino médio quanto para a formação profissional a ele associada, que permitia a realização de ações mais integradas entre ambos.

Vale mencionar também o Plano Nacional da Educação (PNE), estabelecido em 2001 (lei n. 10.172), com base no qual foram definidas, em termos legais, diversas metas a serem atingidas no ensino médio até 2011. Entre elas ressaltam-se:

- Oferecer vagas que, no prazo de cinco anos, correspondam a 50\% e, em dez anos, a 100\% da demanda por ensino médio, em decorrência da universalização e da regularização do fluxo de alunos no ensino fundamental; 
- Melhorar o aproveitamento dos alunos do ensino médio, de forma que atinjam níveis satisfatórios de desempenho definidos e avaliados pelo Sistema Nacional de Avaliação da Educação Básica (SAEB), pelo Exame Nacional do Ensino Médio (ENEM) e pelos sistemas de avaliação que venham a ser implantados nos estados;

- Reduzir, em 5\% ao ano, a repetência e a evasão, de forma que se diminua para quatro anos o tempo médio para conclusão desse nível;

- Assegurar, em cinco anos, que todos os professores do ensino médio possuam diploma de nível superior, oferecendo, inclusive, oportunidades de formação, nesse nível de ensino, àqueles que não a realizaram;

- Promover, no prazo de um ano, padrões mínimos nacionais de infraestrutura, compatíveis com as realidades regionais.

Recentemente, foi aprovada a emenda constitucional n. 59/2009, que vem assegurar a obrigatoriedade de estudo de crianças e adolescentes dos 4 aos 17 anos, fortalecendo com isso a intenção de universalizar o ensino médio à população brasileira e contribuindo para que sua especificidade, como etapa final da educação básica, seja reforçada.

É possível depreender, do conjunto de instrumentos normativos do ensino médio analisados, que há uma preocupação crescente com a ampliação desse nível de ensino, bem como com uma melhor definição dos seus propósitos e, ademais, com a melhoria da qualidade do ensino ofertado. No entanto, sua situação atual ainda se encontra distante das metas propostas no PNE (2001-2011).

\section{Demografia atual}

Com a expansão do ensino fundamental, ocorrida nos anos 1980 e 90, o ensino médio sofreu significativa pressão, em meados da década passada, por ampliação de vagas. Se no período dos anos 1980 a taxa de crescimento de matrículas nesse nível de ensino ficou em torno de 34\%, na década de 1990 esse percentual subiu para 243\%. De um total de 2819 milhões de alunos matriculados em 1980, passou-se para 8193 milhões em 2000 e 8369 milhões em 2007 (Instituto Nacional de Estudos e Pesquisas Educacionais Anísio Teixeira - INEP - Sistema de Consulta a Matrícula do Censo Escolar).

Cabe observar que a expansão do ensino médio, intensificada em meados dos anos 1990, ocorreu no Brasil como um todo, ou seja, cresceu quantitativamente nas cinco grandes regiões geográficas do país. De 1991 a 2000, as matrículas dobraram nas Regiões Sul e Sudeste, onde sua cobertura já era maior, e alcançaram um crescimento de $131 \%$ na Região Nordeste e 183\% na Região Norte. Desde então o ritmo diminuiu. De 2000 a 2007, a matrícula no ensino médio cresceu $32 \%$ e $29 \%$ nas Regiões Centro-Oeste e Nordeste, respectivamente, e caiu 15\% na Região Sudeste. Em termos nacionais, o crescimento da matrícula nesse nível de ensino tem sido negativo desde 2005, fenômeno explicado, de acordo com o INEP, especialmente por conta da queda no crescimento populacional e pelo aperfeiçoamento no sistema de levantamento de dados. 
No caso do ensino médio, apesar da significativa expansão por que passou nos últimos anos, ainda se está muito distante de sua universalização, mesmo nas Regiões Sul e Sudeste do país. Um olhar mais atento às taxas de escolarização permite entender melhor a situação atual. Observa-se que, nacionalmente, no grupo de pessoas com idade de cursar o ensino médio (15 a 17 anos), a taxa de frequência era de 82,2\%, em 2006, variando de 79,1\% na Região Norte a 85,2\% na Região Sudeste. Todavia, a taxa de frequência líquida (adequação entre a série frequentada e a idade) era de apenas 45,3\%, em 2005 (IBGE, 2005; 2006).

Essa situação é um reflexo dos problemas de fluxo, ainda presentes no ensino fundamental, especialmente a repetência, que terminam por adiar o ingresso dos estudantes no ensino médio. Estima-se que apenas metade dos alunos que ingressam no ensino fundamental consegue concluí-lo em um tempo médio de dez anos. Consequentemente, muitos alunos chegam ao ensino médio fora da faixa etária dos 15 aos 17 anos. De acordo com o Censo Escolar de 2007, 56\% dos alunos que frequentavam o ensino médio estavam na faixa etária ideal, 37\% tinham entre 18 e 24 anos e $7 \%$ mais de 25 anos. Novamente, essa tendência acentua-se nas Regiões Norte e Nordeste, onde $60 \%$ dos alunos do ensino médio possuem 18 anos ou mais; na Região Centro-Oeste, esse percentual cai para 40\%, na Sudeste para 35\% e na Sul, para $30 \%$.

Diante desses dados acerca do perfil etário dos jovens do ensino médio, ganha maior relevância observar também qual a sua oferta no período noturno, como alternativa para o aluno-trabalhador. Segundo o Censo Escolar de 2007, do total de matrículas no ensino médio, $41 \%$ estão concentradas no noturno, indicando uma taxa de atendimento nesse turno próxima ao percentual de alunos com idade acima de 17 anos (44\%).

Em termos administrativos, importa ressaltar que o crescimento da matrícula ocorreu principalmente no setor público, mais especificamente na rede estadual. Em termos nacionais, o setor privado, inclusive, diminuiu sua participação. Se, em 1997, esse setor era responsável por 20\% das matrículas oferecidas no ensino médio, em 2007 esse percentual caiu para 10,7\%, enquanto a rede estadual, antes responsável por 72,5\%, passou a atender a $86,5 \%$ dos alunos matriculados, indicando um aumento do peso e da responsabilidade do poder público estadual nesse nível.

Com relação às condições de infraestrutura das escolas, ainda se observa a necessidade de maior investimento para assegurar os elementos básicos ao seu funcionamento. Se, por um lado, aspectos fundamentais como abastecimento de água e de energia elétrica foram praticamente universalizados, por outro lado, elementos como biblioteca e quadra de esportes ainda não se encontram presentes em todas as escolas. Na Região Sul, 95\% das escolas possuem bibliotecas, ao passo que na Região Nordeste essa taxa cai para 68\%, ou seja, um terço das escolas na região não possuem bibliotecas. A oferta de laboratório de ciências e de informática, assim como o acesso à internet também é, ainda, consideravelmente restrito. Nas Regiões Norte e Nordeste, apenas um quarto das escolas possui laboratório de ciências (INEP, 2006). 
Nesse contexto e nessas condições, cabe analisar, por fim, qual o desempenho escolar dos alunos no ensino médio. O Índice de Desenvolvimento da Educação Básica (IDEB), criado em 2007 para avaliar a qualidade do ensino, combinando os dados de desempenho dos alunos com o fluxo escolar, traz uma situação que também merece atenção. Em 2007, o IDEB para os alunos do $3^{\circ}$ ano do ensino médio regular foi de 3,5 , em uma escala que vai de 0 a 10 . A média de desempenho dos alunos nas provas de língua portuguesa e matemática foi de 4,4 e a taxa média de aprovação foi de 78\%. Tal quadro de fluxo dos alunos, ao longo das séries que compõem o ensino médio, associado às dificuldades de acompanhamento dos estudos, que certamente se acumulam com o passar dos anos, fizeram com que a taxa de conclusão ficasse em apenas 50\% (INEP, 2006).

Percebe-se, com base nesse breve diagnóstico, que a permanência do estudante no ensino médio envolve um conjunto de fatores que podem facilitar ou não esse processo, tais como: idade com que ingressam na escola; inclusão ou não no mercado de trabalho; trajetória escolar anterior; taxas de repetência e evasão; aproveitamento dos estudos; infraestrutura oferecida; qualidade do corpo docente, entre outros. Nesse sentido, qualquer política direcionada a esse nível de ensino e ao seu alunado precisa ser pensada de modo que considere, integradamente, esses múltiplos aspectos.

\section{Novas perspectivas}

Em consonância com as direções indicadas pela legislação na área, especialmente pelo PNE, observa-se que algumas políticas recentes vêm convergindo para a redefinição e o fortalecimento do ensino de nível médio. Entre elas, ressaltam-se: a aprovação e a implantação do Fundo de Manutenção e Desenvolvimento da Educação Básica e de Valorização dos Profissionais da Educação (FUNDEB), ${ }^{1}$ por meio da emenda constitucional n. 53/06, seguida da lei n. 11.494/07, incorporado ao Plano de Desenvolvimento da Educação (PDE), apresentado no mesmo ano pelo governo federal, juntamente com outras ações que abrangem não só a educação básica, mas também o ensino superior.

O FUNDEB, ao garantir um financiamento específico para todas as etapas da educação básica, inclusive o ensino médio, de acordo com o número de alunos matriculados nas respectivas redes de ensino, pode representar uma nova possibilidade de expansão desse nível, em direção à sua universalização. Entre as outras ações do PDE, mencionam-se o Programa Brasil Profissionalizado, por meio do decreto n. 6.302/07, que visa fomentar a oferta do ensino médio integrado à educação profissional, permitindo a inserção profissional no mercado de trabalho, com estágio supervisionado, e fortalecer as redes estaduais de ensino na oferta de educação profissional de nível médio, por meio de um programa de assistência técnica e de financiamento.

Definidas tais políticas no âmbito da melhoria das condições financeiras e de infraesturutura do ensino médio, compreende-se a valorização, a reflexão e a difusão de

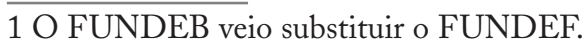


experiências que estejam direcionadas a construir, para esse nível de ensino, uma nova concepção e uma nova organização curriculares, mais atentas às mudanças em nossa sociedade e às demandas de seu público diversificado.

Nesse sentido, a fim de colaborar com a consolidação das políticas de fortalecimento do ensino médio, especialmente em termos da melhoria de sua qualidade, da superação das desigualdades de oportunidades e da universalização do acesso e da permanência, o Ministério da Educação apresentou, em 2009, o Programa do Ensino Médio Inovador, de apoio técnico e financeiro aos estados. Seu objetivo central é superar a dualidade do ensino médio, definindo-lhe uma nova identidade integrada, na qual se incorporem seu caráter propedêutico e seu caráter de preparo para o trabalho. Quer-se estimular a reorganização curricular da escola, de modo a superar a fragmentação do conhecimento, reforçando-se a flexibilização do currículo e desenvolvendo uma articulação interdisciplinar, por áreas de conhecimento, com atividades integradoras definidas com base nos quatro eixos constitutivos do ensino médio - trabalho, ciência, tecnologia e cultura. Desse modo, propõe-se um currículo organizado não apenas em torno de disciplinas, mas também de ações, situações e tempos diversos, assim como de espaços intra e extraescolares, para realização de atividades que favoreçam a iniciativa, a autonomia e o protagonismo social dos jovens.

O Programa quer promover o desenvolvimento de inovações pedagógicas das escolas públicas, de modo a fomentar mudanças necessárias na estrutura curricular dessa etapa educacional, bem como o reconhecimento da singularidade dos sujeitos a que atende. Desse modo, foram definidas algumas condições iniciais básicas para orientar os projetos das escolas:

a Carga horária mínima de três mil horas;

b Centralidade na leitura como elemento basilar de todas as disciplinas, privilegiando-se, nessa prática, a utilização e a elaboração de materiais motivadores, assim como a orientação docente;

c | Estímulo às atividades teórico-práticas desdobradas em laboratórios de ciências, matemática e outros que apoiem processos de aprendizagem nas diferentes áreas do conhecimento;

d | Fomento de atividades de artes para promover a ampliação do universo cultural do aluno;

e | Mínimo de $20 \%$ da carga horária total do curso em atividades optativas e disciplinas eletivas a serem escolhidas pelos estudantes;

f | Atividade docente com dedicação exclusiva à escola;

g | Projeto Político-Pedagógico implementado com a participação efetiva da comunidade escolar e organização curricular articulada com os exames do Sistema Nacional de Avaliação do Ensino Médio.

Em síntese, o Programa Ensino Médio Inovador (2009) expressa a preocupação do Ministério da Educação em responder às mudanças ocorridas ao longo das últimas 
décadas nesse nível de ensino e sugere a urgência de se repensar sua proposta curricular, tornando-a adequada à singularidade do alunado, de forma comprometida com as múltiplas necessidades sociais e culturais da população brasileira.

Outra política recente do MEC que merece ser registrada são as alterações feitas no Exame Nacional do Ensino Médio (ENEM). Por meio da Portaria n. 109/2009, o ENEM tem seus objetivos ampliados, conforme consta do art. $2^{\circ}$.:

I - oferecer uma referência para que cada cidadão possa proceder à sua autoavaliação com vistas às suas escolhas futuras, tanto em relação ao mundo do trabalho quanto em relação à continuidade de estudos;

II - estruturar uma avaliação ao final da educação básica que sirva como modalidade alternativa ou complementar aos processos de seleção nos diferentes setores do mundo do trabalho;

III - estruturar uma avaliação ao final da educação básica que sirva como modalidade alternativa ou complementar a processos seletivos de acesso aos cursos de educação profissional e tecnológica posteriores ao ensino médio e à educação superior; IV - possibilitar a participação e criar condições de acesso a programas governamentais;

$\mathrm{V}$ - promover a certificação de jovens e adultos no nível de conclusão do ensino médio nos termos do art. 38, $\S \S 1^{\circ}$ e $2^{\circ}$ da lei n. 9.394/96 (LDB);

VI - promover avaliação do desempenho acadêmico das escolas de ensino médio, de forma que cada unidade escolar receba o resultado global;

VII - promover avaliação do desempenho acadêmico dos estudantes ingressantes nas instituições de educação superior.

O ENEM assume, desse modo, as funções de: a) avaliação sistêmica, ao subsidiar a formulação de políticas públicas; b) avaliação certificatória, ao aferir conhecimentos para aqueles que estavam fora da escola; c) avaliação classificatória, em relação ao acesso ao ensino superior, ao difundir-se como mecanismo de seleção entre as instituições de ensino superior, articulado agora também ao Sistema Unificado de Seleção (SISU). Diante dessa reconfiguração do exame e da expansão do número de inscritos, ${ }^{2}$ cabe observar o impacto dessa política da definição do currículo efetivamente em vigência nas escolas de ensino médio no país.

2 De acordo com informações divulgadas no site do Ministério da Educação em agosto de 2010, o ENEM ampliou seu espectro de atendimento de 156 mil inscritos, em 1998, para 4,6 milhões, em 2009. 


\section{O DEBATE EM TORNO DAS DIRETRIZES CURRICULARES NACIONAIS DO ENSINO MÉDIO - 1998}

No contexto brasileiro da década de 1990, os debates na área educacional foram marcados por uma nítida polarização entre defensores e críticos das reformas políticas e econômicas implementadas pelo governo Fernando Henrique Cardoso (FHC). Predominaram, nesse momento, estudos que privilegiavam abordagens teóricas macroeconômicas e análises estruturais que buscavam revelar a sintonia existente entre as medidas adotadas pelo governo no país e as orientações de organismos multilateriais, como Banco Internacional de Reconstrução e Desenvolvimento (BIRD), o Fundo Monetário Internacional (FMI) e Banco Interamericano de Desenvolvimento (BID), entre outros. Nesse cenário, as DCNEM e, posteriormente, os Parâmetros Curriculares Nacionais do Ensino Médio, são identificados como parte dessa reforma do ensino médio e criticados, principalmente, por seguirem a mesma direção e pressupostos da reforma da educação e do Estado realizadas no Brasil nos anos 1990, fortemente marcados pelo ideário neoliberal (cf. Bueno, 2000; Cunha, 2000; Frigotto e Ciavatta, 2002; Ferretti e Silva Jr., 1998; Kuenzer, 1997, 2000, 2001; Martins, 2000).

O objetivo central da maioria das análises desenvolvidas acerca das DCNEM de 1998 era desvendar o caráter ideológico do discurso oficial e as contradições entre a visão de ensino médio presente nas diretrizes e as demais políticas colocadas em prática pelo governo (cf. Kuenzer, 2000; Bueno, 2000; Domingues et al., 2000). À primeira vista, as diretrizes traziam um discurso sedutor e inovador, por meio da valorização de uma concepção de "educação para a vida e não mais apenas para o trabalho"; da defesa de um ensino médio unificado, integrando a formação técnica e a científica, o saber fazer e o saber pensar, superando a dualidade histórica desse nível de ensino; de um currículo mais flexível e adaptado à realidade do aluno e às demandas sociais; de modo contextualizado e interdisciplinar; baseado em competências e habilidades. Contudo, ao analisar-se o contexto mais amplo das políticas para o ensino médio em curso à época, o que se percebia era uma realidade muito distinta daquela proposta pelas diretrizes. Além disso, após um estudo mais detalhado do discurso presente nas DCNEM, o que se percebia era um texto híbrido que, em vários momentos, acabava por ressignificar certos termos a tal ponto destes assumirem sentidos quase que opostos aos originais.

Em termos do referencial teórico-metodológico, além das análises macroestruturais, que faziam uso de um quadro teórico marxista, particularmente gramsciano, nos estudos realizados sobre o discurso explícito e implícito nas diretrizes também se identificam metodologias de análise de conteúdo, tomando como referência principal os trabalhos de Laurence Bardin (1977). Vale mencionar, contudo, o número ainda reduzido de pesquisas empíricas que se propuseram a acompanhar a efetiva implementação das diretrizes, tanto nos sistemas de ensino quanto nas escolas (cf. Zibas, 2005b). 
Dentre as principais críticas realizadas às DCNEM, nesse conjunto de pesquisas realizadas sobre o tema, ${ }^{3}$ ressaltam-se três delas, identificadas como as mais recorrentes: a) a subordinação da educação ao mercado, ressignificando conceitos como flexibilização, autonomia e descentralização; b) a permanência da separação entre formação geral e formação para o trabalho; c) o poder de indução relativamente limitado das diretrizes.

Como afirmado anteriormente, um dos principais objetivos dos estudos realizados sobre as DCNEM aprovadas ao final da década de 1990 foi explicitar a real intenção do governo com as reformas adotadas para a educação. Dentro de um contexto de reforma do Estado, cujas políticas pretendiam torná-lo mais enxuto em termos de suas responsabilidades sociais e mais permeável às parcerias com a iniciativa privada, $\mathrm{o}$ que se observou foram mudanças propostas para a área da educação que acabaram por subordinar esta à lógica econômica e às demandas do mercado de trabalho. Particularmente no caso do ensino médio e das diretrizes propostas para esse nível de ensino, isso pode ser percebido no discurso que enfatiza a necessidade de um currículo cada vez mais flexível, para se adequar a um mundo produtivo em constante transformação e cada vez mais instável, que agora demanda uma qualificação para a "vida": “[...] preparar para a vida significava desenvolver competências genéricas e flexíveis, de modo que as pessoas pudessem se adaptar facilmente às incertezas do mundo contemporâneo" (Ramos, 2004, p. 39).

Desse modo, conceitos como flexibilidade, autonomia e descentralização, construídos no campo educacional como formas de emancipação e construção de uma consciência crítica, são ressignificados nesse novo contexto:

[...] nas reformas dos sistemas de ensino aparecem conceitos e propostas tais como descentralização; autonomia dos centros escolares; flexibilidade dos programas escolares; liberdade de escolha de instituições docentes; necessidade de formação continuada; superação do conhecimento fragmentado [...]. Esses conceitos encontram correspondência nas características da reorganização do mundo produtivo: na descentralização das grandes corporações industriais; na autonomia relativa de cada fábrica em decorrência do processo de desterritorialização das unidades de produção e/ou de montagem; na flexibilidade da organização produtiva para se ajustar à variabilidade de mercados e de consumidores. (Santomé, 1998, p. 21 apud Martins, 2000, p. 72)

Tais conceitos são criticados nas DCNEM, particularmente, por serem associados à proposta de um currículo baseado em competências e habilidades, o que reforçaria a subordinação da educação às demandas do mundo do trabalho, que passa a exigir um trabalhador polivalente responsável por sua própria empregabilidade:

3 Ver Zibas (2005a) para uma síntese das principais análises realizadas sobre as DCNEM de 1998. 
Há um privilégio [nas DCNEM] conferido ao discurso das competências e à possibilidade de avaliação constante dos sujeitos sociais: os saberes são mobilizados visando à formação de desempenho e sua expressão em um saber-fazer. [...] Tem-se a valorização do desempenho, do resultado e da eficiência social (desenvolver competências é estar apto a se inserir de forma eficiente no mercado de trabalho). [...] Com o slogan de que a "escola agora é para a vida", reduz-se vida ao atendimento das exigências do trabalho no mundo globalizado, ao contexto no qual são aplicadas as competências. (Lopes, 2004a, p. 199-200)

Outro aspecto muito analisado nos estudos sobre as DCNEM diz respeito à própria concepção de ensino médio presente no documento, particularmente no que se refere à possibilidade de um currículo integrado, que supere a dualidade entre uma formação para a continuidade dos estudos e uma formação para o trabalho, debate que marcou a história desse nível de ensino no Brasil.

Observou-se, nesse sentido, que o discurso oficial presente no parecer e na resolução que estabelece as DCNEM anuncia o fim dessa separação, reforçando a ideia de um currículo comum que abrangeria uma formação básica e a preparação para o trabalho, compreendendo esta como algo mais amplo do que educação profissional:

Artigo 12 - Não haverá dissociação entre a formação geral e a preparação básica para o trabalho, nem esta última se confundirá com a formação profissional.

$\S 1^{\circ} \mathrm{A}$ preparação básica para o trabalho deverá estar presente tanto na base nacional comum como na parte diversificada.

$\S 2^{\circ} \mathrm{O}$ ensino médio, atendida a formação geral, incluindo a preparação básica para o trabalho, poderá preparar para o exercício de profissões técnicas, por articulação com a educação profissional, mantida a independência entre os cursos. (Brasil,1998a)

Contudo, as pesquisas na área criticam duramente essa suposta ruptura da dualidade do ensino médio propalada pelas DCNEM. Por um lado, questiona-se a noção de trabalho presente nas diretrizes; por outro, observa-se a contradição entre o discurso presente na lei e as práticas políticas do governo federal para o ensino médio.

No primeiro caso, parte-se da defesa de um projeto unitário para o ensino médio, superando a disputa com a educação profissional, que deveria ser integrada a esse nível de ensino, para se criticar a forma como o trabalho é definido no texto das diretrizes. Observa-se que há uma oscilação nas DCNEM "entre trabalho como princípio e trabalho como contexto; trabalho como mediação e trabalho como fim; trabalho como práxis humana e trabalho como práxis produtiva" (Ramos, 2004, p. 41). Desse modo, em vez de se superar a dicotomia entre ensino propedêutico e ensino profissionalizante, o que as diretrizes fazem é reduzir a concepção geral de trabalho a uma função utilitária, onde este é assumido como princípio educativo na perspectiva do capital e não do trabalhador (idem, p. 42).

Outro questionamento se refere ao contexto no qual são aprovadas as DCNEM, em especial ao impacto do decreto n. 2.208/97 para a organização curricular do ensino 
médio. Analisando o discurso oficial presente nas diretrizes, percebe-se que estas reforçam a visão de ensino médio também presente na lei n. 9.394/96, ao estabelecer a especificidade desse nível de ensino, construída em torno de um núcleo comum a todos, ao mesmo tempo em que permitem uma diversificação, em possível articulação com a educação profissional. Contudo, esse discurso contrasta com a orientação dada pelo decreto n. 2.208/97, que separa novamente o ensino médio da educação profissional, ao estabelecer trajetórias distintas e independentes para ambos, reforçando assim a dualidade que se dizia superada (cf. Martins, 2000; Frigotto; Ciavatta, 2004).

Ainda em relação ao debate sobre a identidade do ensino médio, vale ressaltar uma nova polarização que começou a se configurar nas críticas às DCNEM de 1998, particularmente quando do início da primeira gestão do governo Lula (2003-2006). Essa nova discussão situa em outro patamar a defesa ou crítica a um currículo nacional comum para o ensino médio:

[...] de um lado, há uma defesa muito firme de uma escola média que, mesmo respeitando as diferenças, tenha um perfil universal, calcado nas proposições de Gramsci quanto à politecnia, combinando 'trabalho, ciência e cultura na sua prática e nos seus fundamentos científico-tecnológicos e histórico-sociais' (Frigotto; Ciavatta, 2004b, p. 18) ou, dito de outra forma, uma escola que garanta oo direito de acesso aos conhecimentos socialmente construídos, tomados em sua historicidade, sobre uma base unitária que sintetize humanismo e tecnologia' (Ramos, 2004, p. 41). [...]

A tal argumentação contrapõe-se outra concepção de currículo, que talvez se possa identificar como "pós-moderna", defendida na mesma coletânea por Lopes (2004a), segundo a qual a validade universal de qualquer conhecimento transmitido pela escola é uma falácia, uma vez que: É preciso sempre lembrar que a própria ideia de universal é uma invenção humana, situada em determinado momento histórico. O fato de um conhecimento ser considerado universal só se estabelece porque existem pessoas e relações sociais aos quais essa universalidade interessa. Se a perspectiva atual é construir um outro projeto de educação e de sociedade, penso ser preciso começar questionando os padrões "universais" de conhecimento escolar até hoje instituídos (p. 203). Nessa abordagem, não há possibilidade de um currículo nacional e, portanto, descarta-se o princípio da escola unitária. Além disso, entendido como política cultural, o currículo deve abordar o trabalho apenas como uma questão entre muitas outras (tais como: gênero, sexualidade, juventude, violência, lazer etc.), deixando de ser o princípio educativo por excelência proposto por Gramsci. (Zibas, 2005b, p. 1080-1082)

Para Zibas (2005b), tal debate traz à luz "diferenças teóricas e político-ideológicas inconciliáveis", explicitando divergências que não estavam muito claras durante o governo de Fernando Henrique Cardoso (1995-2002), quando as críticas às políticas desse governo aglutinavam grande parte da comunidade acadêmica (cf. Zibas, 2005b, 
p. 1080). Neste novo debate que se instala, a crítica à dualidade do ensino médio, construída pela oposição entre formação geral e formação para o trabalho e a defesa de um currículo nacional unitário, que teria no princípio do trabalho sua base comum, deixa de ser algo consensual. Ao invés de um currículo único, reforça-se a importância de trajetórias diversificadas no ensino médio, onde a formação técnica seria apenas uma dentre outras possíveis trajetórias. Desse modo, da crítica à dualidade no ensino médio, passou-se à defesa da multiplicidade e diversidade do currículo disponível aos jovens nesse nível de ensino.

Por fim, um último ponto também recorrente nas críticas dirigidas às DCNEM diz respeito ao seu efetivo alcance e poder de indução como política curricular. Um primeiro aspecto observado nesse sentido abrange a distância entre o discurso normativo e diretivo do Estado e as práticas efetivas dos atores, responsáveis por operacionalizar as diretrizes nos sistemas de ensino e nas escolas (cf. Martins, 2000). Qual o poder efetivo do governo central? Na prática, o que se tem observado é que as políticas curriculares têm sido pouco assimiladas nos sistemas de ensino estaduais e municipais e nas escolas brasileiras:

No Brasil, apesar da importância que os governos dão ao planejamento curricular, a história tem demonstrado que, sucessivamente, as reformas "fracassam". É o que demonstra a maioria dos estudos acerca, por exemplo, das reformas de 1960 (lei n. 4.024/61) e 1970 (lei n. 5.692/71). Por que elas fracassaram? Será que os mesmos equívocos se repetem na atual reforma do Ensino Médio? Naquelas, o insucesso se deveu, basicamente, à ausência de financiamento do processo de manutenção e investimento e à falta de uma política "agressiva" de formação de professores e de recursos humanos em geral. Deveu-se também à ausência de uma política de adequação do espaço e da infraestrutura pedagógica, além da inexistência de uma política editorial que superasse o passado. (Domingues et al., 2000, p. 64)

Como indicam os aspectos identificados no estudo citado anteriormente, observa-se em geral uma falta de continuidade nas políticas curriculares nacionais, que se caracterizariam mais como "programas de governo, isto é, com início e fim determinados pelos mandatos. Falta tempo para sua implantação e consolidação no espaço de um governo, acarretando descontinuidade administrativa e pedagógica" (idem, ibidem). Esse parece ser o caso também das DCNEM de 1998 e dos PCNEM de 1999.

Ainda em relação ao poder indutivo das DCNEM, vale observar a questão federativa e a liberdade de organização da educação atribuída aos estados e municípios. De acordo com a LDB de 1996, em seu artigo 9., inciso IV, a União é responsável, em articulação com os estados e municípios, pelo estabelecimento de competências e diretrizes para a educação básica, que deverão orientar os currículos e seus conteúdos mínimos. Na organização curricular das DCNEM, foram reservados 25\% da carga horária para que as escolas e/ou Secretarias de Educação estaduais definissem os conteúdos a serem oferecidos para atender aos interesses diversificados e inclinações de seus 
alunos. Há, em ambos os documentos, a ideia de uma corresponsabilidade entre os entes federativos. Contudo, essa divisão de competências nem sempre tem sido muito bem equacionada. Além disso, a LDB reforça a ideia já presente na Constituição Federal de 1988 da autonomia de concepções pedagógicas que se atribui às escolas, o que limita a adoção de uma única concepção pedagógica em âmbito nacional, como pretendiam os PCNs para o ensino fundamental (cf. Azanha, 1996).

\section{NOVAS DIRETRIZES CURRICULARES PARA O ENSINO MÉDIO?}

Duramente criticadas por grupos contrários às políticas do governo $\mathrm{FHC}$, novas diretrizes curriculares para o ensino médio já vinham sendo propostas desde a aprovação das DCNEM em 1998. Contudo, tal debate se consolida e entra na agenda do poder público com o início da gestão do governo Lula. Em 2003, a Secretaria de Educação Média e Tecnológica (SEMTEC), do MEC, iniciou uma série de discussões e consultas sobre o tema que culminou no Seminário Nacional "Ensino Médio: Construção Política”, cujas principais discussões foram publicadas em livro em fevereiro de 2004. Posteriormente, a Secretaria de Educação Básica (SEB), da qual a educação de nível médio passa a fazer parte, iniciou uma revisão dos PCNEM, consultando diversos especialistas no assunto, o que culminou nas Orientações Curriculares Nacionais para o Ensino Médio, publicadas em 2006. Em 2009, o Ministério da Educação convidou um conjunto de especialistas para auxiliá-lo no processo de revisão e atualização das diretrizes curriculares nacionais para a educação básica como um todo, incluindo o ensino médio. Em 2010, o documento resultante desse trabalho foi apresentado pelo MEC ao Conselho Nacional de Educação como base para o início da definição de novas diretrizes para a área. Em julho de 2010, foram aprovadas as Diretrizes Curriculares Nacionais para a Educação Básica (parecer CNE/CEB n. 7/2010 e resolução CNE/ CEB n. 4/2010) e, em maio de 2011, foi aprovado parecer estabelecendo novas diretrizes curriculares especificamente para o ensino médio (parecer CNE/CEB n. 5/2011).

Diante de todo esse processo de revisão das DCNEM, que novidades o documento aprovado traz para a organização curricular do ensino médio no Brasil? Quais as mudanças efetivamente propostas para esse nível de ensino? Mais especificamente, que diálogo é possível identificar, no texto das novas diretrizes, com as críticas que vinham sendo feitas ao antigo documento aprovado em 1998?

Em termos da organização propriamente dita do ensino médio, as DCNEM-2011 basicamente referendam os principais marcos normativos já vigentes na área e os programas e ações que vinham sendo adotados como política educacional para esse nível de ensino, tanto no âmbito federal quanto em alguns estados e municípios. No início do parecer, é feita uma síntese das orientações legais que impactam direta ou indiretamente o ensino médio. As principais mudanças ressaltadas abrangem a aprovação da lei n. 11.741/08, que reforça a integração entre o ensino médio e a educação profissional, da lei n. 11.494/07, que garante um financiamento específico a esse nível de ensino por meio 
do FUNDEB e da emenda constitucional n. 59/2009, que assegura a obrigatoriedade de estudo de crianças e adolescentes dos 4 aos 17 anos.

Com respeito ao contexto político, social e educacional, avalia-se no parecer das novas DCNEM que o cenário no qual se insere o ensino médio é distinto daquele existente em 1998, ao vivermos um momento de crescimento econômico e de mais investimentos na área educacional no país. Contudo, essa visão contrasta com certa estagnação do ensino médio nos anos 2000, especialmente em termos do contingente de estudantes que se matricularam e/ou concluíram esse nível de ensino. A explicação dada no parecer para essa situação é que teríamos um ensino médio pouco atraente, que não atenderia nem à demanda de formação para o trabalho, nem à de formação para a cidadania. Ou seja, em termos da estrutura do ensino médio, esta permaneceria inadequada às necessidades tanto da sociedade quanto dos jovens que o frequentam, sendo necessário um currículo menos rígido. Nesse sentido, apesar de vivenciarmos um contexto político e social aparentemente distinto, os grandes temas e preocupações presentes no documento das DCNEM da década de 1990 permanecem os mesmos nas novas diretrizes: a busca por uma identidade específica para esse nível de ensino; a inadequação de sua estrutura às necessidades da sociedade; a proposição de um currículo mais flexível; e a valorização da autonomia das escolas na definição do currículo.

As novas DCNEM apontam como seu objetivo central possibilitar a definição de uma grade curricular mais atrativa e flexível, capaz de atrair o aluno para o ensino médio e combater a repetência e a evasão. Nessa direção, sugere-se uma estrutura curricular que articule uma base unitária com uma parte diversificada, que atenda à multiplicidade de interesses dos jovens. Vale ressaltar, por exemplo, o ensino médio noturno e na modalidade de educação de jovens e adultos (EJA), que tem a possibilidade de organizar 20\% do seu currículo a distância e com menor carga horária diária e anual, mantido o mínimo total de horas (2.400 horas no caso do ensino regular e 1.200 horas em EJA). Também o ensino direcionado à população indígena, do campo, quilombola, de educação especial e em regime de liberdade assistida tem a possibilidade de uma organização diferenciada, de acordo com a legislação específica. Já no ensino diurno, reforça-se a possibilidade da educação em tempo integral, abrangendo um mínimo de 7 horas diárias. Por último, em relação à educação profissional, é dada ênfase a um currículo que integre a formação de nível médio à formação profissional.

Contudo, essas possibilidades apresentadas pelas DCNEM-2011 não são novidades; tanto a LDB de 1996 quanto as legislações posteriores aprovadas em âmbito nacional já permitiam tal organização. Qual a relevância, portanto, das novas DCNEM? $\mathrm{O}$ que as diretrizes parecem trazer de novo tem menos a ver com o campo normativo e mais com as políticas de governo, ao trazerem a indicação de diversos programas do governo federal na área da educação, apresentados como exemplos para a adoção do modelo curricular proposto: 
Destaque-se que há redes escolares com Ensino Médio que já vêm desenvolvendo formas de oferta que atendem às indicações acima, inclusive com ampliação da duração e da carga horária do curso e com organização curricular flexível e integradora. São exemplos desse comportamento as escolas que aderiram aos Programas Mais Educação e Ensino Médio Inovador, ambos incentivados pelo MEC na perspectiva do desenvolvimento de experiências curriculares inovadoras. (Parecer CNE/CEB n. 5/2011-Diretrizes Curriculares Nacionais do Ensino Médio)

Tais programas do governo federal parecem assumir o papel de definidores de uma proposta curricular nacional para as escolas de ensino médio. Contudo, diante da autonomia dada aos estados e municípios pelo nosso sistema federativo, o tom do texto das DCNEM é muito mais de sugestão e tentativa de convencimento do que diretivo. Pretende-se, com os diagnósticos e soluções apresentadas, sensibilizar e orientar os sistemas de ensino e as escolas, mas cabe a estes decidir se seguem ou não as sugestões propostas. Ao que parece, a capacidade das diretrizes de induzir novas políticas curriculares dependerá em grande parte da ampliação dos programas do MEC e dos recursos disponíveis de modo que se alcance a adesão de estados e municípios.

Se, por um lado, as DCNEM-2011 não trazem novidades em relação à organização curricular do ensino médio, por outro é nítida a mudança na linguagem e nos referenciais teóricos presentes no documento aprovado, indicando uma sintonia entre o texto das novas diretrizes e as principais críticas realizadas às antigas diretrizes.

Um primeiro aspecto que vale ser mencionado é a crítica à subordinação da educação ao mercado de trabalho, muito presente nas antigas diretrizes por meio da ênfase na necessidade de flexibilização do currículo e na avaliação baseada em competências e habilidades. Em relação à avaliação com base em competências e habilidades, esse modelo difundiu-se e é adotado em praticamente todos os sistemas nacionais de avaliação da educação e também é reafirmado nas novas diretrizes. Tal proposta aparece associada à preocupação com um excesso de conteúdos curriculares, visto como prejudicial à organização do ensino médio. Contudo, essa orientação contrasta com o crescente número de "componentes curriculares" 4 que hoje, legalmente, devem ser trabalhados no ensino médio, ainda que não necessariamente no formato de disciplinas: língua portuguesa; língua materna, para populações indígenas; língua estrangeira moderna; arte, em suas

4 Considerando outros (pareceres CNE/CEB n. 16/2001 e n. 22/2003), o parecer CNE/CEB n. 38/2006 assinalou que não há, na LDB, relação direta entre obrigatoriedade e formato ou modalidade do componente curricular (seja chamado de estudo, conhecimento, ensino, matéria, conteúdo, componente ou disciplina). Indicou também que, quanto ao formato de disciplina, não há sua obrigatoriedade para nenhum componente curricular, seja da base nacional comum, seja da parte diversificada. As escolas têm garantida a autonomia quanto à sua concepção pedagógica e para a formulação de sua correspondente proposta curricular, sempre que $\mathrm{o}$ interesse do processo de aprendizagem assim o recomendar, dando-lhe o formato que julgarem compatível com a sua proposta de trabalho. 
diferentes linguagens: cênicas, plásticas e, obrigatoriamente, a musical; educação física; matemática; biologia; física; química; história; geografia; filosofia; sociologia; história e cultura afro-brasileira e indígena; língua espanhola; educação alimentar e nutricional; o processo de envelhecimento, o respeito e a valorização do idoso; a educação ambiental; a educação para o trânsito; a educação em direitos humanos.

Apesar do considerável aumento no número de "componentes curriculares" do ensino médio nos últimos anos, mantém-se nas novas diretrizes o discurso da necessidade de um currículo mais flexível, menos engessado. Ao mesmo tempo, o termo "flexibilização", fortemente criticado nas DCNEM de 1998, é agora substituído pela expressão "diversidade". Este termo é usado no parecer das DCNEM de 2011 com múltiplos significados: em alguns momentos, refere-se às políticas de diferença e identidade cultural; em outros, à variedade de interesses dos jovens de modo geral; e em várias ocasiões, aparece também como sinônimo de flexibilização.

O uso da palavra "diversidade" parece surgir no texto das novas DCNEM como uma tentativa de acomodação de duas concepções distintas de currículo e da própria identidade do ensino médio. No parecer das DCNEM-2011, o desafio de se encontrar uma especificidade para o ensino médio não está mais na superação de dicotomias como a formação para o trabalho versus a formação para o ensino superior - por meio da construção de um currículo unificado, mas sim pela afirmação de uma multiplicidade de significados e trajetórias possíveis de serem construídas ao longo do ensino médio. A acomodação de tensões e divergências gerou um modelo curricular que associa uma base unitária com uma parte diversificada, em que a formação profissional é apenas mais uma entre as várias formações possíveis:

A definição da identidade do Ensino Médio como etapa conclusiva da Educação Básica precisa ser iniciada mediante um projeto que, conquanto seja unitário em seus princípios e objetivos, desenvolva possibilidades formativas com itinerários diversificados que contemplem as múltiplas necessidades socioculturais e econômicas dos estudantes, reconhecendo-os como sujeitos de direitos no momento em que cursam esse ensino. (Parecer DCNEM, 2011)

Para além das desigualdades sociais que antes diferenciavam o currículo no ensino médio entre aqueles que teriam de postergar o ingresso no mercado de trabalho e aqueles que já estavam nele inseridos, as novas diretrizes trazem ao debate as múltiplas identidades desses jovens e suas distintas realidades sociais, culturais, etárias etc.:

Tanto na base nacional comum quanto na parte diversificada, a organização curricular do Ensino Médio deve oferecer tempos e espaços próprios para estudos e atividades que permitam itinerários formativos opcionais diversificados, a fim de melhor responder à heterogeneidade e pluralidade de condições, múltiplos interesses e aspirações dos estudantes, com suas especificidades etárias, sociais e culturais, bem como sua fase de desenvolvimento. (Parecer CNE/CEB n. 5/2011 - Diretrizes Curriculares Nacionais do Ensino Médio) 
Essa proposta de currículo e identidade definidas para o ensino médio, que the atribuem um caráter tanto unificado quanto diversificado, parece ser a principal mudança trazida pelas novas DCNEM em 2011, ao mesmo tempo em que seu maior desafio, especialmente em termos de sua consolidação nas ações efetivas dos sistemas de ensino e das escolas.

\section{CONSIDERAÇÕES}

O ensino médio vem passando por diversas transformações na sua forma de organização, estrutura, objetivos e currículo, algumas mais amplas, outras menos perceptíveis. Um aspecto que tem permeado o debate sobre esse nível de ensino, quase desde a sua origem no Brasil, é a sua própria identidade, questão que ganha hoje maior relevância. $\mathrm{O}$ ensino médio, ao passar de educação intermediária, situada até então entre a educação obrigatória e a superior, à última etapa da educação básica obrigatória, parece ser um dos grandes desafios atuais na formulação de políticas públicas educacionais.

Após uma rápida expansão nos anos 1990, o acesso ao ensino médio tem se mantido estagnado nos últimos dez anos, juntamente com altas taxas de evasão e repetência, associadas a um baixo desempenho dos alunos em testes nacionais de avaliação. Nesse cenário, a questão da organização curricular, particularmente na forma das novas DCNEM, reaparece como um aspecto importante para mudar esse quadro, especialmente na ênfase em uma proposta mais flexível e diversificada de currículo, que seja capaz de se adequar aos distintos interesses dos jovens.

As DCNEM aprovadas em 2011 inserem-se em um contexto político, social e educacional distinto daquele vivido na década de 1990; contudo, algumas das críticas realizadas na época parecem continuar relevantes hoje. Em termos da especificidade do ensino médio, cabe observar os desafios inerentes à construção de uma identidade própria aos estudos realizados nesse nível, ao mesmo tempo em que se garante uma multiplicidade e diversidade de trajetórias possíveis. Essa questão nos remete, ainda, à possibilidade de construção de um currículo nacional para o ensino médio e também à indagação sobre onde este será definido, se por meio de diretrizes curriculares estabelecidas no âmbito do CNE e do MEC ou se de forma indireta, através de exames e avaliações do desempenho dos alunos, como parece ser a função do ENEM em seu novo formato. A capacidade das DCNEM de induzirem novas políticas curriculares, especialmente nas esferas estaduais e municipais e mesmo nas escolas, é outro aspecto que merece atenção e maior aprofundamento por parte dos estudos na área, particularmente diante da questão federativa no país. Nesse sentido, vale observar, por último, que ainda precisamos ampliar e aprofundar os debates teóricos nesse campo, com um foco no próprio ensino médio e nas suas especificidades, que não se restrigem à educação profissional, além de analisar o impacto dessas políticas nos sistemas de ensino e nas escolas, com mais estudos de base empírica, que talvez identifiquem as ressignificações e reapropriações feitas nesse âmbito das políticas curriculares formuladas nacionalmente. 


\section{REFERÊNCIAS}

Azanha, José Mário P. Parecer sobre os Parâmetros Curriculares Nacionais para o ensino médio. São Paulo: Conselho Estadual de Educação de São Paulo, 1996.

BARDIn, Laurence. Análise de conterido. Lisboa: Edições 70, 1977.

Brasil. Decreto n. 2.208, de 17 de abril de 1997. Regulamenta o parágrafo 2o do art. 36 e os art. 39 a 42 da Lei n. 9.394, de 20 de dezembro de 1996, que estabelece as diretrizes e bases da educação nacional. Diário Oficial da União, Brasília, DF, 18 abr. 1997. p. 7.760.

. Conselho Nacional de Educação (CNE). Resolução n. 3, de 26 de junho de 1998. Institui as Diretrizes Curriculares Nacionais para o Ensino Médio. Diário Oficial da República Federativa do Brasil, Brasília, DF, 5 ago. 1998a.

. Conselho Nacional de Educação (CNE). Parecer n. 15, de 1 de junho de 1998.

Diretrizes Curriculares Nacionais para o Ensino Médio. Brasília, DF, 1998b.

. Ministério da Educação. Orientações curriculares do ensino médio. Brasília, DF, 2004.

. Conselho Nacional de Educação (CNE). Resolução n. 1, de 3 de março de 2005. Atualiza as Diretrizes Curriculares Nacionais Definidas pelo Conselho Nacional de Educação para o Ensino Médio e para a Educação Profissional Técnica de nível médio às disposições do Decreto n. 5.154/2004. Diário Oficial da República Federativa do Brasil, Brasília, DF, 11 mar. 2005.

Bueno, Maria S. S. Orientações nacionais para a reforma do ensino médio: dogma e liturgia. Cadernos de Pesquisa, São Paulo: Fundação Carlos Chagas; Campinas: Autores Associados, n. 109, p. 7-23, mar. 2000.

Cunha, Luiz A. Ensino médio e ensino técnico na América Latina: Brasil, Argentina e Chile. Cadernos de Pesquisa, São Paulo: Fundação Carlos Chagas; Campinas: Autores Associados, n. 111, dez. 2000.

Domingues, José L. et al. A reforma do ensino médio: a nova formulação curricular e a realidade da escola pública. Educação E̋ Sociedade, Campinas: UNICAMP; Campinas: CEDES, ano XXI, n. 70, abr. 2000.

Ferreti, Celso J.; Silva Junior, João R. Trabalho, formação e currículo: para onde vai a escola? São Paulo: Xamã, 1998.

Frigotto, Gaudêncio; Ciavata, Maria. (Org.). A experiência do trabalho e a educação básica. Rio de Janeiro: DP\&A, 2002.

. (Org.). Ensino médio: ciência, cultura e trabalho. Brasília, DF: MEC/SEMTEC,

2004.

Ibge - Instituto Brasileiro de Geografia e Estatística. Programa Nacional por Amostra de Domicilios (PNAD). 2005.

. Programa Nacional por Amostra de Domicílios (PNAD). 2006.

Revista Brasileira de Educação $\quad$ v. 17 n. 49 jan.-abr. 2012 
Inep - Instituto Nacional de Estudos e Peseutsas Educacionais Anísio Teixeira. Sistema de Consulta a Matrícula do Censo Escolar. 2006.

KuENZer, Acacia Z. Ensino médio e profissional: as políticas do Estado neoliberal. São Paulo: Cortez, 1997.

. O ensino médio agora é para a vida: entre o pretendido, o dito e o feito. Educação E' Sociedade, Campinas: UNICAMP; Campinas: CEDES, ano XXI, n. 70, abr. 2000.

LOPES, Alice C. Interpretando e produzindo políticas curriculares para o ensino médio. In: Frigotto, Gaudêncio; Ciavatta, Maria. (Org.). Ensino médio: ciência, cultura e trabalho. Brasilia, DF: MEC; SEMTEC, 2004a.

. Políticas curriculares: continuidade ou mudança de rumos? Revista Brasileira de Educação, Rio de Janeiro: ANPEd; Campinas: Autores Associados, n. 26, p. 109-118, 2004b.

Martins, Angela M. Diretrizes Curriculares Nacionais para o Ensino Médio: Avaliação de Documento. Cadernos de Pesquisa, São Paulo: Fundação Carlos Chagas; Campinas: Autores Associados, n. 109, p. 67-87, mar. 2000.

Pinto, José M. O ensino médio. In: Oliveira, R. P. e Adrião, T.(Org.). Organização do ensino no Brasil: níveis e modalidades na Constituição Federal e na LDB. São Paulo: Xamã, 2002.

Ramos, Marise N. O projeto unitário de ensino médio sob os princípios do trabalho, da ciência e da cultura. In: Frigotto, Gaudêncio; CiavatTa, Maria. (Org.). Ensino médio: ciência, cultura e trabalho. Brasilia, DF: MEC; SEMTEC, 2004.

Romanelu, Otaíza. de O. História da educação no Brasil (1930/1973). Petrópolis: Vozes, 2001. ZiBAS, Dagmar M. L. A reforma do ensino médio nos anos 1990: o parto da montanha e as novas perspectivas. Revista Brasileira de Educação, Rio de Janeiro, n. 28, p. 24-36, 2005 a.

. Refundar o ensino médio? Alguns antecedentes e atuais desdobramentos das políticas dos anos de 1990. Educaşão E̋ Sociedade, Campinas: UNICAMP; Campinas: CEDES, vol. 26, n. 92 [Especial], p. 1067-1086, out. 2005b.

\section{SOBRE A AUTORA}

Sabrina Moehlecke é doutora em educação pela Universidade de São Paulo (USP). Professora adjunta da Universidade Federal do Rio de Janeiro (UFRJ). E-mail: sabrina.moehlecke@gmail.com

Recebido em novembro de 2011

Aprovado em dezembro de 2011 


\section{SABRINA MOEHLECKE}

\section{O ensino médio e as novas diretrizes curriculares nacionais: entre recorrências e novas inquietações}

Em maio de 2011, o Conselho Nacional de Educação aprova parecer que estabelece novas diretrizes curriculares nacionais para o ensino médio no Brasil. Diante dos múltiplos olhares e perspectivas a partir das quais é possível analisar as atuais políticas para o ensino médio, pretende-se, neste ensaio, identificar o que as novas diretrizes curriculares trazem de novo para a organização do ensino médio no Brasil. Desse modo, a primeira parte do texto é dedicada à contextualização de algumas das principais mudanças pelas quais passou o ensino médio no país, especialmente em termos legais, das condições de acesso e permanência e das políticas na área. Em seguida, são identificadas as principais críticas feitas às DCNEM de 1998 nos estudos e pesquisas realizadas sobre o assunto desde então para, ao final do artigo, se analisar até que ponto as novas diretrizes dialogam com esses questionamentos e inquietações, quais as novas possibilidades de organização do ensino médio que trazem para o país e que desafios continuam na agenda de debates.

Palavras-chave: ensino médio; currículo; políticas públicas; diretrizes curriculares nacionais.

Secondary education and the new national curriculum directions: between old recurrence and new inquires

In May 2011, the National Council of Education has established new national curriculum directions for secondary education (NCESE) in Brazil. Considering the multiple 
views and perspectives from with it is possible to analyze the current policies toward secondary education in the country, this essay pretends to identify what is new in these curriculum directions for the organization of this level of education in Brazil. In the first part of this article, we analyze the context of some major changes of secondary education in the last years, especially in the legislation, access conditions and policies for this level of education. In the next part, we identify the main critics directed to NCESE, approved in 1998, particularly in the researches developed about this issue. Finally, we analyze if the new directions for curriculum in secondary education dialogue with the questions and inquires developed by these researches, which new possibilities of organization the new NCESE provides for this level of education and which challenges continues in debate in the national educational agenda regarding secondary education in Brazil.

Keywords: secondary education; curriculum; public policies; national curriculum directions.

\section{La enseñanza media y las nuevas directrices curriculares nacionales: entre recurrencias y nuevas inquietudes}

En mayo del 2011, el Consejo Nacional de Educación aprueba el parecer que establece nuevas directrices curriculares nacionales para la enseñanza media en Brasil. A partir de estas perspectivas es posible analizar las actuales politicas para la enseñanza media, se pretende, en este ensayo, identificar lo que las nuevas directrices curriculares traen de nuevo para la organización de la enseñanza media en Brasil. De este modo, la primera parte del texto es dedicada a la contextualización de algunos de los principales cambios por los cuales pasó la enseñanza media en el país, especialmente en términos legales, de las condiciones de acceso y permanencia y de las politicas en el área. En seguida, son identificadas las principales críticas hechas a las DCNEM de 1998 en los estudios y pesquisas realizadas sobre el asunto desde entonces para, al final del artículo, analizarse basta qué punto las nuevas directrices dialogan con esos cuestionamientos e inquietudes, cuáles son las nuevas posibilidades de organización de la enseñanza media que traen para el país y qué desafios continúan en la agenda de debates.

Palabras clave: enseñanza media; currículo; políticas públicas; directrices curriculares nacionales. 